\title{
El alcázar de Medina de Pomar y la Casa del Cordón. La creación de un palacio especializado nobiliario*
}

\author{
Elena Paulino Montero \\ Universidad Complutense de Madrid \\ elena.paulino@ghis.ucm.es
}

\section{RESUMEN}

El proceso de especialización de los palacios que se desarrolla a finales de la Edad Media ha sido generalmente estudiado partiendo de los ejemplos regios. No obstante, los palacios nobiliarios también participaron de esa evolución y crearon sus propios modelos. Este artículo pretende abordar el estudio de este proceso partiendo de las construcciones de la familia Velasco. En sus palacios principales, Medina de Pomar y la Casa del Cordón, construidos con un siglo de diferencia, se observa la progresiva codificación de los espacios, la incorporación de novedades arquitectónicas de otras tradiciones y la evolución propia de los palacios castellanos para adaptarse a las nuevas necesidades específicas.

Palabras clave: Palacio especializado, Medina de Pomar, Casa del Cordón, Velasco, Cogolludo.

\section{The alcazar of Medina de Pomar and the Casa del Cordón: the creation of the specialized noble palace}

\begin{abstract}
In the Late Middle Ages, both royal and noble palaces were in a process of specialization of spaces and functions. This development has normally been studied taking as examples the royal palaces, but noble palaces also participated in this evolution. This article focuses on the palaces of the Castilian noble family Velasco as a case of study. Two main palaces, Medina de Pomar and la Casa del Cordon, were built at the end of the fourteenth and fifteenth century respectively, and in them we can perceive the evolution in the creation of specialized spaces, the adoption of features coming from other architectural tradition and the process of adaptation to the new social and ceremonial needs.
\end{abstract}

Key words: Specialized palace, Medina de Pomar, Casa del Cordón, Velasco family, Cogolludo.

\footnotetext{
* Esta investigación se inscribe en el marco del proyecto I+D "La Génesis del Estado Moderno y el Palacio Especializado: Castilla y Granada en la Baja Edad Media" (HAR2009-08901). Quiero agradecer a su director, Juan Carlos Ruiz Souza, a Miguel Sobrino y Daniel Montes Noguera sus sugerencias durante la elaboración de este artículo.
} 
A finales del siglo XIV y comienzos del siglo XV, se desarrolló un proceso de especialización paulatina de los palacios que generalmente ha sido estudiado desde el punto de vista de los palacios de la realeza, pero que incluyó también los palacios nobiliarios. Desde este punto de partida, este artículo propone abordar el estudio de los dos principales palacios de una de las familias más importantes de la Baja Edad Media castellana: los Velasco. Estos palacios son los de Medina de Pomar, iniciado hacia 1370, y la Casa del Cordón en Burgos, cuya construcción comenzó un siglo después. Ambos han sido muy transformados a lo largo del tiempo y han sufrido sucesivas, y en ocasiones agresivas, restauraciones. Sin embargo, contamos con suficientes datos que, si bien no permiten hacer una reconstrucción detallada, sí permiten observar sus características principales y los cambios que se produjeron a lo largo de un siglo en la configuración de sus espacios.

\section{El alcázar de Medina de Pomar}

Medina de Pomar, situada en la merindad de Castilla Vieja, era una villa de realengo, tal y como aparece en el Becerro de las Behetrías donde se especifica que "este lugar es del rey e siempre fue de los reyes". Pasó a formar parte del señorío de los Velasco por donación real en 1369, tras la subida al trono de Enrique II de Trastámara. Los Velasco convirtieron esta villa en el centro físico y simbólico de su señorío, en un gran centro de gestión de la memoria familiar con la construcción de un monasterio, un panteón funerario y el mencionado alcázar que debió comenzarse hacia 1370 , poco después de la donación de la villa, y del que sabemos estaba terminado en 1380 , fecha de fundación del mayorazgo en el que aparece citado por primera vez.

Este alcázar fue levantado en un momento muy específico de la historia familiar. Pedro (I) Fernández de Velasco había sido hombre de confianza del rey Pedro ${ }^{1}$ hasta 1360, tras la derrota de Araviana, cuando huyó de Castilla y pasó al servicio de Enrique de Trastámara. Este cambio de bando durante la guerra fue de gran importancia para la familia Velasco ${ }^{2}$, como para muchas otras familias nobles castellanas que con la entronización de los Trastámara recibieron tierras, juros, privilegios y mejoraron su posición en la corte. En el caso que nos ocupa, Pedro fue nombrado camarero mayor, un puesto que heredaron sus hijos y nietos, y recibió, entre otras tierras, las villas de Briviesca y de Medina de Pomar, centro jurisdiccional de la merindad de Castilla Vieja donde se situaba el núcleo principal del señorío familiar.

\footnotetext{
1 Es significativo que Pedro Fernández de Velasco estuviera residiendo en Sevilla y Carmona como protector de Aldonza Coronel mientras ésta fue amante del rey. Vid. LÓPEZ DE AYALA, Crónicas y Memorias de los Reyes de Castilla: Rey don Pedro, Madrid, 1779, p. 235.

2 Aunque el despegue económico, social y político de los Velasco había comenzado cien años antes. C. JULAR PÉREZ-ALFARO, "Dominios señoriales y relaciones clientelares en Castilla: Velasco, Porres y Cárcamo (siglos XII-XIV)", Hispania, LVI, 192 (1996), pp. 131-171; y "Nobleza y relaciones clientelares: el caso de los Velasco", C. JULAR y C. ESTEPA (coords.), Los señoríos de behetría, Madrid, 2000, pp. 145-186; y "Nobility and patronage: The Velascos a case of study", C. JULAR y C. ESTEPA (coords.), Land, Power and Society in Medieval Castile. A study of "Behetria" Lordship, Turnhout, 2009, pp. 177-227.
} 


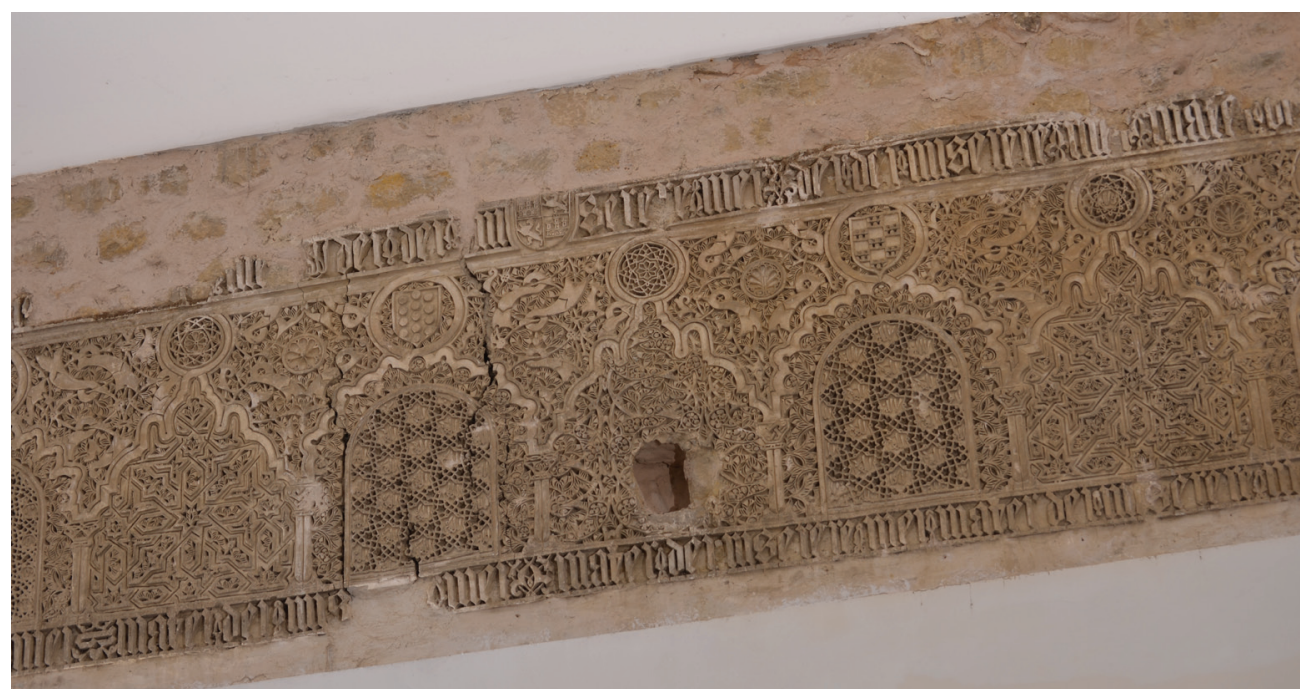

Fig. 1. Yeserías de la torre sur. Planta noble. Alcázar de Medina de Pomar, Burgos.

Por tanto, los Velasco afianzaron su posición política y social, con un nuevo cargo en la corte y nuevas rentas y tierras que aseguraban su preponderancia social ${ }^{3}$. Su señorío se amplió enormemente, incluyendo villas relativamente importantes, y afirmaron su presencia en la Merindad de Castilla Vieja, espacio en el que se agrupaban la mayor parte de sus posesiones y que aspiraban a dominar por completo. Acompañando todo este proceso, se produjo un fenómeno de "recentralización" del señorío. Los primitivos lugares de asentamiento familiar pasaron definitivamente a un segundo plano y Medina de Pomar se convirtió en el nuevo centro físico y simbólico del señorío, que debía ser marcado como tal.

En este contexto, los Velasco construyeron en Medina de Pomar su nuevo espacio de representación que, por un lado, plasmaba su idea de poder $\mathrm{y}$, por otro, les permitía ejercerlo físicamente, puesto que contaba con una sala para la administración de la justicia, una pequeña cárcel y un espacio para el archivo y para el tesoro ${ }^{4}$.

Exteriormente era un edificio con aspecto fortificado adosado a la muralla de la vi$11 \mathrm{a}^{5}$, compuesto por dos potentes torres unidas por un edificio alargado central, rodea-

3 Pedro recibió un gran número de tierras y poblaciones del rey. Por ejemplo, en 1371 el príncipe heredero le otorgó Quintana de la Cuesta, Valdivieso, Valdemanzanedo, Santotí, Bustillo, Moneo, Tobalina, Quintana Martín Galíndez, Cormezana, Lozares, Bascuñuelos, Leciñana, Costaja, los monasterios de Mena, Lezana y Leciñana, así como Tintueces y Bortedo. Todas en zonas que sus antepasados habían comenzado a dominar.

4 Vid. M. SOBRINO GONZÁLEZ, "El alcázar de los Velasco, en Medina de Pomar (Burgos). Un espacio áulico andalusí en el Norte de la Vieja Castilla" Loggia, 11 (2001), pp. 10-21. Aporta datos sobre el uso de la cárcel y el empleo del alcázar como lugar de intimidación e imposición del poder señorial A. MORENO OLLERO, "Gobierno y actuación de los Velasco en la merindad de Castilla Vieja a fines de la Edad Media", Estudios de Historia y de Arqueología Medievales, X (1994), pp. 121-137.

5 Vid. I. CADIÑANOS BARDECI, Arquitectura fortificada en la Provincia de Burgos, Burgos, 1987, pp. 170-175, aunque las relaciones que el autor establece entre esta situación junto a la cerca de la villa y la 
do por un foso y decorado con los escudos familiares de los Velasco y los Sarmiento, el matrimonio constructor. Este modelo arquitectónico se adaptaba perfectamente a la imagen de fuerza y poder militar que los Velasco estaban interesados en proyectar, en un momento de afianzamiento de su posición privilegiada y de consolidación territorial de sus dominios, que se habían visto incrementados notablemente.

Esta imagen se complementaba con la decoración interior, donde diversos elementos remitían a la arquitectura real de la segunda mitad del siglo XIV, tanto nazarí como castellana. Entre estos elementos habría que citar las techumbres de madera, hoy desaparecidas, cuyas huellas en los muros han permitido su reconstrucción hipotética ${ }^{6}$. También destacaban las ricas yeserías de la planta noble, parcialmente conservadas (fig.1) y que han sido puestas en relación con las de la Casa Olea y el Alcázar de Sevilla ${ }^{7}$. Y sobre todo destacaba el espacio de la planta noble de la torre sur (fig.2): era una qubba, es decir, una estructura centralizada cubierta por una techumbre ochavada de madera, que transmitía una clara imagen de prestigio y de fuerte poder político $^{8}$. Todos estos elementos andalusíes se incorporaron a la arquitectura palatina castellana asociados a la idea de refinamiento, lujo y magnificencia y, en su alcázar, los Velasco contribuyeron a la creación de una imagen de poder del linaje, diseñada para legitimar y exhibir su nuevo estatus.

Por otra parte, la aparición de algunos de estos elementos andalusíes, empleados en los palacios reales en las décadas anteriores, suponía una novedad en la arquitectura palatina de la nobleza del momento. Así sucede con la qubba y con las yeserías, que seguían modelos nazaríes y que Pedro Fernández de Velasco habría incorporado tras su estancia en los palacios de Pedro I en Sevilla y Carmona9 ${ }^{9}$. Junto a estas innovaciones peninsulares, también se incorporaron otras ultrapirenaicas. Es el caso de la

arquitectura fortificada islámica deben ser matizadas. En el Catastro del Marqués de la Ensenada se especifica que contaba con foso, contrafoso y "un pozo con bastante caudal de agua". Citado por J. GARCÍA SÁINZ DE BARANDA, Medina de Pomar como lugar arqueológico y centro de turismo de las Merindades de Castilla la Vieja, Burgos, 1966, pp. 22-23.

6 Para su reconstrucción vid. M. SOBRINO GONZÁLEZ, op. cit., 2001.

7 R. AMADOR DE LOS RÍOS, Burgos en España. Sus monumentos y artes. Su naturaleza e Historia. Barcelona, 1888, pp. 1042-1044 fue el primero que estudió las yeserías y estableció la comparación con el Alcázar de Sevilla. Lo sigue M.L. CONCEJO DÍAZ, El arte mudéjar en Burgos y su provincia, Tesis Doctoral Inédita, Universidad de Castilla la Mancha, 1999, pp. 43-44. Relacionan estas yeserías con la casa Olea M. SOBRINO GONZÁLEZ, op. cit., 2001, p. 18 y J.C. RUIZ SOUZA, "El Palacio especializado y la Génesis del Estado Moderno. Castilla y Al-Andalus en la Baja Edad Media", J. PASSINI y R. IZQUIERDO BENITO, La ciudad medieval: de la casa principal al palacio urbano, Toledo, 2011, pp. 93-128.

8 Sobre la qubba nazarí, sus connotaciones y su transmisión a la arquitectura castellana vid. R. MANZANO MARTOS, La qubba, aula regia en la Espańa musulmana, Madrid, 1994; J.C. RUIZ SOUZA, "Castilla y AlAndalus. Arquitecturas aljamiadas y otros grados de asimilación" Anuario Del Departamento de Historia y Teoría del Arte, XVI (2004), pp. 17-43; A. SERRA DESFILIS, "La imagen construida del poder real en la Corona de Aragón (siglos XIII-XV): Casas, ceremonial y magnificencia", Res Publica, 18 (2007), pp. 35-57; A. ALMAGRO GORBEA, Palacios medievales hispanos. Discurso de ingreso en la Real Academia de San Fernando. Madrid, 2008; y "La Qoubba de Sidi Qasim et ses précédentes andalous", Cartas De La Goleta, 3 (2009), pp. 103-149; M.'T. PÉREZ HIGUERA, "Palacios mudéjares castellanos: modelos hispanomusulmanes y tradición gótica", J. PASSINI y R. IZQUIERDO BENITO, La ciudad medieval: de la casa principal al palacio urbano, Toledo, 2011, pp. 19-27; J.C. RUIZ SOUZA, op. cit., 2011, pp. 93-128; y M. SOBRINO GONZÁLEZ, op. cit., 2001, pp. 10-21.

9 Vid. nota 2. 


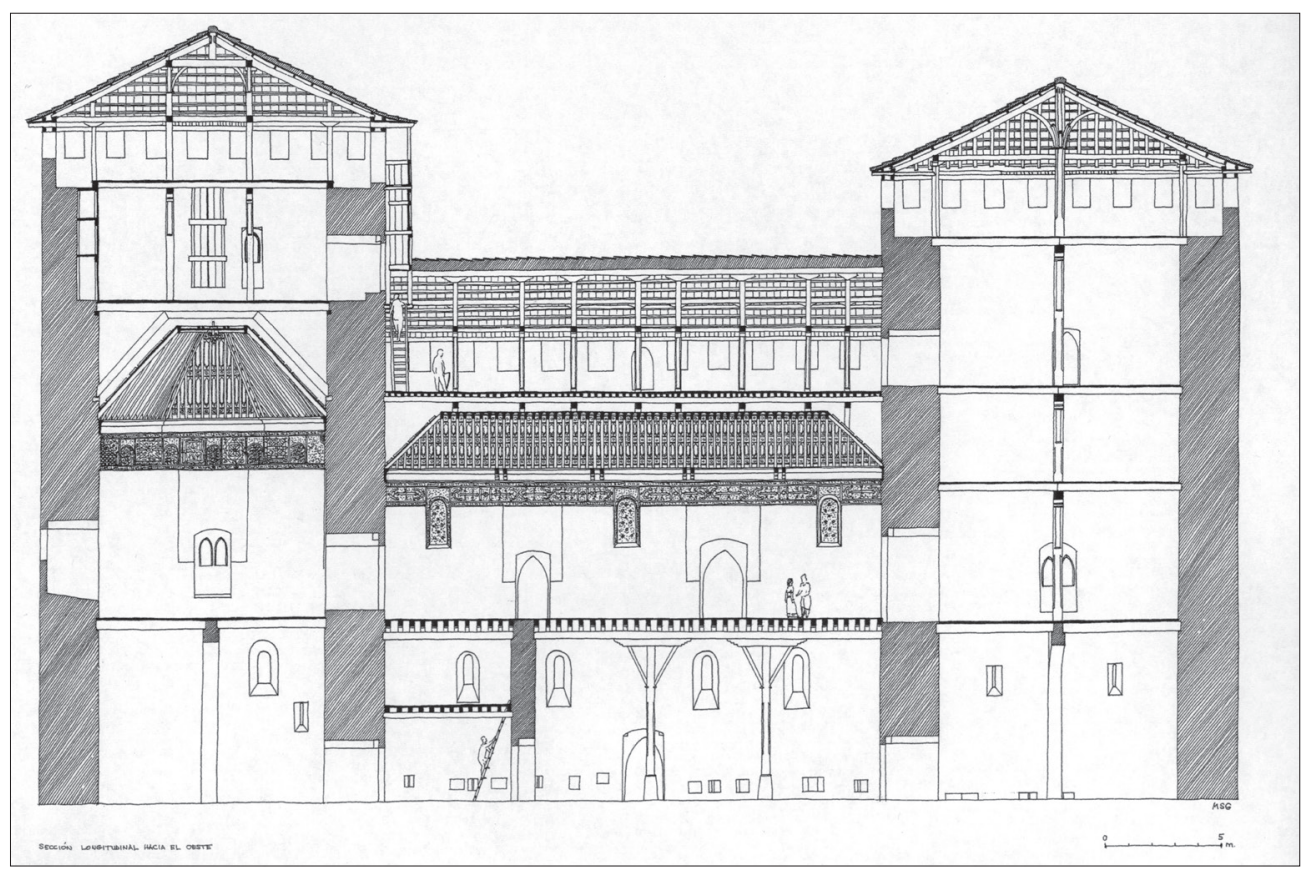

Fig. 2. Reconstrucción de M. Sobrino del interior del Alcázar de Medina de Pomar.

escalera de caracol que se proyecta hacia el exterior en una torre poligonal (fig.3), novedad francesa que apareció en el contexto de las obras del Louvre en la década de $1360^{10}$ y que los nobles franceses estaban incorporando en sus residencias en torno a las fechas de construcción del alcázar castellano ${ }^{11}$.

10 M. WHITELEY, "La Grande Vis. Its development in France from the Mid Fourteenth to the Mid Fifteenth Centuries", L'escalier dans l'architecture de la Renaissance, Paris, 1985, pp. 16-17; y "Deux escaliers royaux du XIVe siècle: les 'Grands degrez' du Palais de la Cité et la 'Grande Viz du Louvre'”, Bulletin Monumental, 147 (1989), pp. 133-154. La proyección marcada hacia el exterior de una escalera de caracol sin duda remitiría a la más moderna arquitectura real francesa. Trata ampliamente este tema y su reflejo en el ámbito navarro J. MARTÍNEZ DE AGUIRRE, "Lancelot en Olite: paradigmas arquitectónicos y referentes literarios en los palacios de Carlos III de Navarra (1387-1425)" en este mismo volumen.

11 Primero entre los palacios de la familia real como Saumur, Germolles o el palacio ducal de Dijon (vid. M. Whiteley op. cit., 1985; J. MESQUI, Châteaux et enceintes de la France Médiévale. De la défense à la résidence, Paris, 1993, t. II, pp. 39 y ss.; y "Les ensembles palatiaux et princiers en France aux XIVe et XVe siècles", A. RENOUX, (ed.), Palais royaux et princiers au Moyen Âge, Le Mans, 1996, pp. 51-70). Entre los palacios nobiliarios habría que citar el palacio de Argentan, c. 1370 (vid. I. CHAVE "Les Châteaux neufs de l'Apanage d'Álençon (1350-1415): Matérialisation du pouvoir d'une famille princière", A.M. FLAMBARD HÉRICHER, Les lieux du pouvoir au Moyen Âge en Normandie et sur ses marges, Caen, 2006, pp. 151-181) y dentro del patrocinio episcopal, la tour des abbés, en Fontvieille, cuya datación habría que retrasar algunos años. 


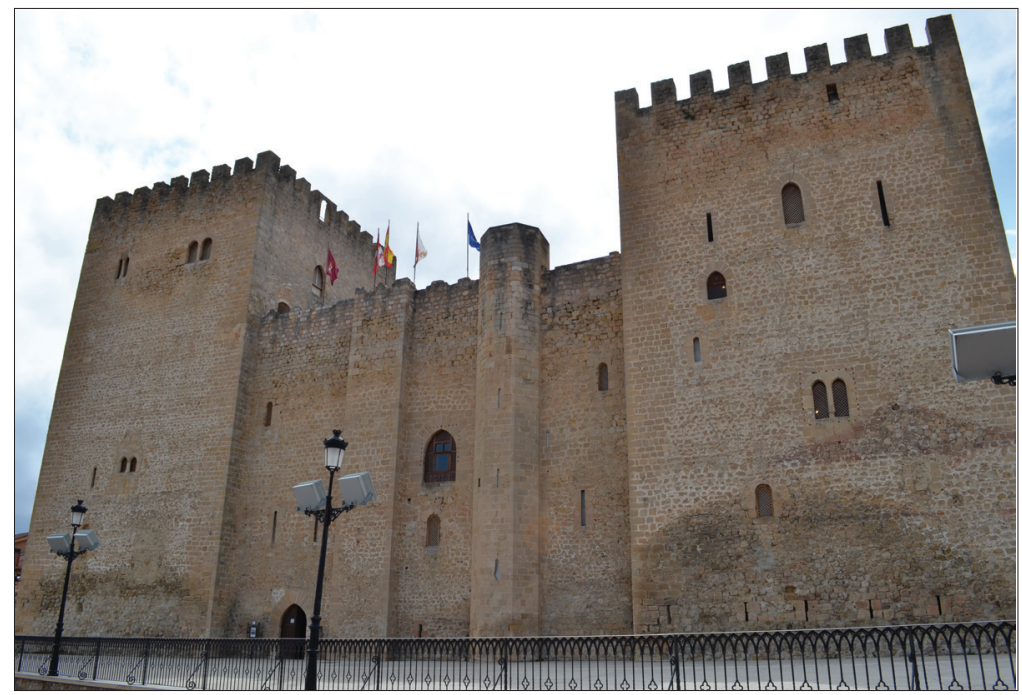

Fig. 3. Exterior del Alcázar de Medina de Pomar.

Esta torre se utilizaba en los palacios franceses para articular los espacios públicos y privados, ya que marcaba el comienzo de los apartamentos reales, y daba acceso a la chambre à parer, sala de recepciones semipública dentro de esta zona ${ }^{12}$. En Medina de Pomar, sin embargo, la escalera no se correspondía con esta compleja organización de salas públicas, semipúblicas y privadas diferenciadas. En el alcázar burgalés, el espacio se dividía en espacios de servicio y salas principales, más que en espacios públicos y privados. En la planta baja estaría la zona de servicios, almacenamiento, la cocina y el pozo ${ }^{13}$. En la primera planta se situaba la zona noble, diferenciada por su programa decorativo, con la gran sala alargada con chimenea, la qubba en la torre sur y sobre ella el archivo. En la torre norte se hallaba la principal escalera de servicio, el cuerpo de guardia, otras estancias de servicio y la cárcel. La escalera de caracol era, por tanto, un medio de comunicación vertical privilegiado, que daba acceso a las salas principales de aparato y que se complementaba con la citada escalera de servicio de la torre norte ${ }^{14}$.

12 Vid. Mary Whiteley, "Le Louvre de Charles V: dispositions et fonctions d'une résidence royale", Revue de l'Art, 97 (1992), pp. 60-71; y "Royal and Ducal Palaces in France in the Fourteenth and Fifteenth Centuries: Interior, Ceremony and Function”, J. GUILLAUME, (ed.), Architecture et Vie Sociale. L'organisation intérieure des grandes demeures à la fin du Moyen Âge et à la Renaissance. Paris, 1994, pp. 47-65; y "Public and private space in royal and princeley chateaux in Late Medieval France", A. RENOUX, Palais royaux et princiers au Moyen Âge, Le Mans, 1996, pp. 71-75; B. BOVE "Les palais royaux à Paris au Moyen Âge (XIe-XVe siècles), M.F. AUZÉPY et J. CORNETTE (dir.), Palais et pouvoirs. De Constantinople à Versailles, 2003, pp. 45-79.

13 Hoy desaparecido pero mencionado en el catastro del Marqués de la Ensenada y todavía presente en un plano del edificio realizado durante las guerras carlistas.

14 Estamos completamente de acuerdo con la reconstrucción que hace M. SOBRINO, op. cit., 2001. 
Como hemos visto, en este alcázar no se puede hablar de salas especializadas o diferenciación de espacios públicos o privados. Las salas principales se caracterizaban por su plurifuncionalidad, pudiendo desempeñar funciones públicas o privadas, albergar banquetes, bailes, recepciones más íntimas... No había una zona residencial diferenciada, ni una sala prevista como capilla. En este sentido recuerda a los espacios descritos en Los Hechos del Condestable don Miguel Lucas de Iranzo, donde las unidades de cámara y sala superpuesta albergan diversas funciones públicas y privadas ${ }^{15} \mathrm{y}$ donde tampoco se menciona capilla puesto que, o bien alguna de las salas se transformaba en pequeño oratorio, o bien el Condestable acudía a la catedral, como los Velasco acudirían durante sus estancias en Medina de Pomar al monasterio de clarisas fundado por sus antepasados.

\section{El palacio del Cordón: un palacio especializado}

Aproximadamente un siglo después de la construcción del Alcázar de Medina de Pomar, los Velasco construyeron la Casa del Cordón en Burgos. Hacia 1476 Pedro (III) Fernández de Velasco, bizniento de los constructores de Medina de Pomar y su mujer, Mencía de Mendoza, comenzaron las obras del nuevo palacio burgalés. Los Velasco habían residido en Burgos de forma intermitente desde mediados del siglo XIV, cuando se documenta su presencia durante largas temporadas en la ciudad, sobre todo en las casas de Cantarranas la Mayor pero también en otras de menor importancia en Cantarranas la Menor y en el barrio de San Esteban ${ }^{16}$.

Estas casas resultaban insuficientes para las nuevas necesidades de representación de la familia, especialmente a partir de 1473, cuando Pedro Fernández de Velasco fue nombrado Condestable de Castilla. Por otra parte, la construcción de un nuevo palacio resultaba aconsejable, puesto que no solo se pretendía fijar la residencia familiar en Burgos, sino también marcar la ciudad como nuevo centro de su señorío. Esta "recentralización" del señorío respondía a una serie de circunstancias que no podemos desarrollar aquí, pero que incluían cambios en los intereses políticos familiares, orientados a afianzar su posición en la corte, y nuevos intereses económicos en la ciudad burgalesa.

15 J. MATA CARRIAZO (ed.), Hechos del Condestable don Miguel Lucas de Iranzo, Madrid, 2009; y F. MARÍAS, "Arquitectura y vida cotidiana en los palacios nobiliarios españoles del siglo XVI", J. GUILLAUME, (ed.) Architecture et vie sociale. L'organisation intérieure de las grandes demeures á la fin du Moyen Âge et á la Renaissance, Tours, 1994, pp. 167-169.

16 Cantarranas la mayor aparece citada ya en el testamento de Pedro I Fernández de Velasco (13 de marzo de 1383. AHN, FRIAS, C.595, D.7) y desde entonces se vincula sistemáticamente por mayorazgo a la herencia del primogénito. Sobre su antigua ubicación y características vid. A.C. IBÁŃEZ PÉREZ, Historia de la Casa del Cordón de Burgos. Burgos, 1987, pp. 30-31. En el testamento de Juan de Velasco (30 de agosto de 1414, AHN, FRIAS, C.539, D.2) se mencionan las casas de Cantarranas la mayor, Cantarranas la menor y la casa de la Vega, que hereda el primogénito, y las casas de la plomería en la collación de San Esteban para el segundogénito. Su hijo, el Buen Conde de Haro, sólo incluyó en su mayorazgo las casas Cantarranas la mayor y de la Vega. Citado por E. GONZÁLEZ CRESPO, Elevación de un linaje nobiliario castellano en la Baja Edad Media: Los Velasco, Tesis Doctoral Inédita, Universidad Complutense de Madrid, 1981, pp. 146-192. 


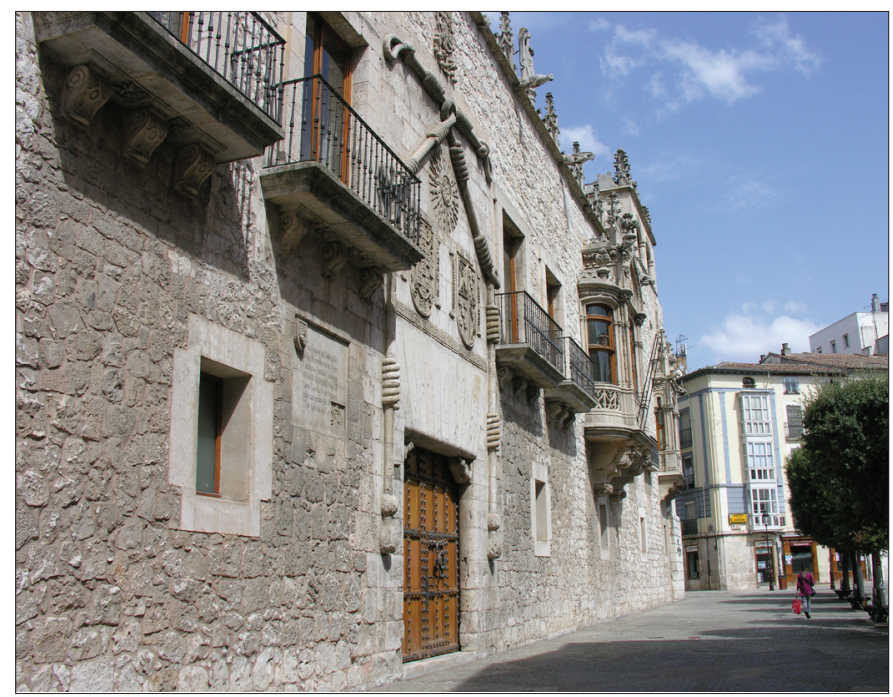

Fig. 4. Exterior de la Casa del Cordón, Burgos.

Este palacio, por tanto, respondía a nuevas necesidades y planteaba nuevos retos. En primer lugar debía integrarse en un complejo urbano que no era parte del señorío pero que se pretendía dominar. Por tanto la fachada (fig.4) se convirtió en un elemento fundamental al exhibir el programa político familiar y los valores con los que se identificaba, en un proceso de exteriorización de la vivienda ${ }^{17}$ en el que el zaguán también desempeñó un importante papel mediador. En segundo lugar, el palacio se convirtió prácticamente desde el inicio ${ }^{18}$ en residencia real, algo que tuvo que pesar en la configuración de los espacios. Tanto desde el punto de vista de su integración urbana como de su función como palacio real, su ubicación en uno de los extremos de una plaza preexistente, la del mercado mayor, resultaba muy conveniente ${ }^{19}$.

La Casa del Cordón tenía una estructura ordenada en torno a dos patios, uno central, que articulaba el núcleo principal de la vivienda, y un patio secundario en torno al que se distribuían las dependencias de servicio. Este patio secundario, hoy desaparecido, se situaba en el extremo norte de la casa y aparece citado en el relato anónimo

17 Siguiendo el término empleado por I.G. BANGO TORVISO, Edificios e imágenes medievales. Historia y significado de las formas, Madrid, 1995.

18 En 1475 se cita el primer aposentamiento de Fernando el Católico para asediar el castillo de Burgos. R. DOMÍNGUEZ CASAS, Arte y etiqueta de los Reyes Católicos. Artistas, residencias, jardines y bosques, Madrid, 1993, pp.302-307.

19 Sobre la plaza del mercado mayor, su configuración urbanística y los cambios provocados por la construcción del palacio vid. A.C. IBÁÑEZ PÉREZ, op. cit., 1987, esp. pp. 27-30; y Arquitectura civil del siglo XVI en Burgos, Burgos, 1977, pp. 288-291. 
del viaje de Felipe el Hermoso y Juana a Castilla en $1501^{20}$, como un lugar en el que en determinados festejos los caballeros podían ir a comer o beber a cualquier hora ${ }^{21}$. En esta zona estarían dispuestas las letrinas, las caballerizas y la cocina o "cuarto del horno"22.

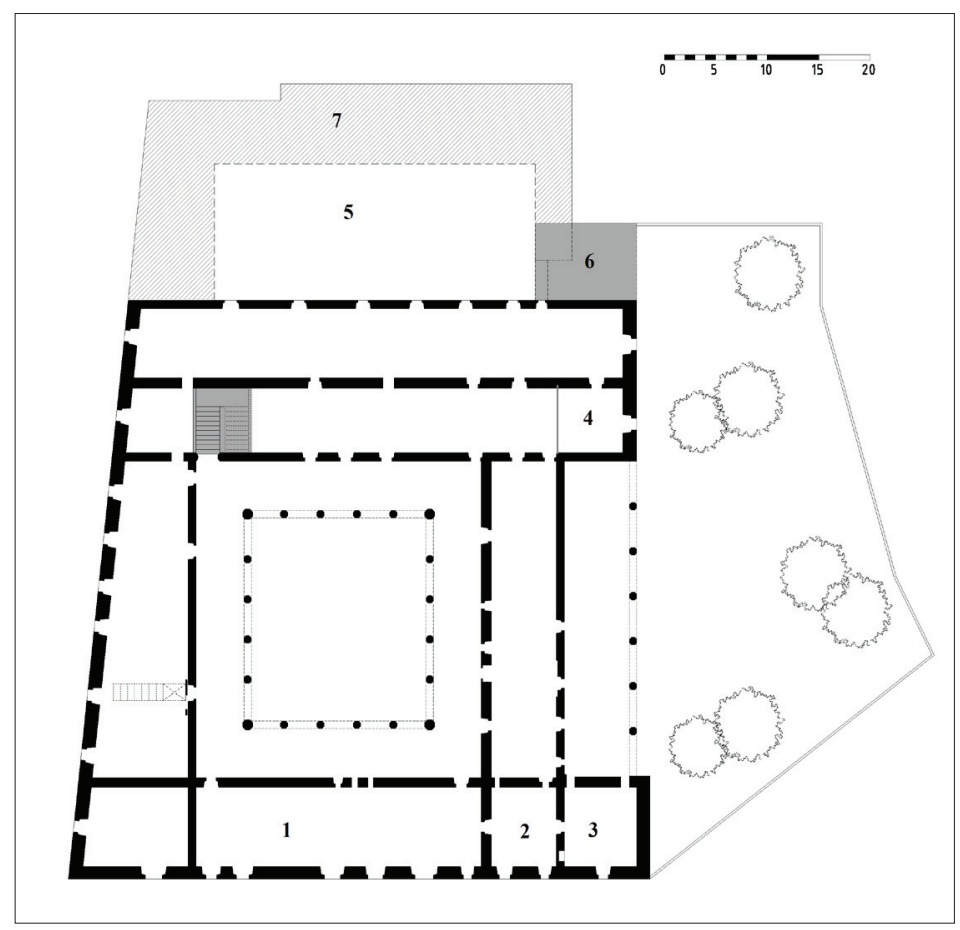

Fig. 5. Reconstrucción hipotética de la planta principal de la Casa del Cordón (Elena Paulino Montero y Daniel Montes Noguera). 1 Sala principal, 2 habitación principal, 3 antesala, 4 capilla, 5 patio de servicios, 6 zona de letrinas, 7 zona de servicios.

El patio principal, que todavía hoy se conserva, estructuraba el núcleo principal de la casa. Se accedía a él desde la calle a través de un zaguán cuya puerta estaba desenfilada respecto al eje central y que probablemente tendría un nivel de suelo inferior al

20 Por tanto consideramos que no se construyó a partir de 1521, como Ibáñez sostiene sino que debió edificarse en la segunda fase, entre 1484 y 1497, cuando el autor burgalés documenta quejas de los vecinos por las obras del Condestable en la trasera de su casa. Vid. A.C. IBÁÑEZ PÉREZ, op. cit., 1987, pp. 38-47.

21 "Et tenoit vne court ouuerte en son hostel aupres de la court ou chacun cheualier despaigne et de nostre terre pouoit aller boire et menger a toutes heures", ANÓNIMO, Reise des Erzherzogs Philipp nach Spanien 1501, transcrito y publicado por J. CHMEL, Die Handschriften der K. K. Hofbibliothek in Wien, Wien, 1841, vol. 2, pp. 554-655. La cita corresponde a la página 614.

22 Aunque la documentación escrita que menciona esta zona es ya de 1601, la disposición de las letrinas, cocina, hornos, etc. no habría cambiado desde el siglo XV. El Condestable Íñigo adquirió nuevos terrenos en la trasera de la casa en 1521 y en ellos se dispondría la denominada "sala de los vidrios", la armería y se ampliarían las dependencias anteriores. Vid. A.C. IBÁÑEZ PÉREZ, op. cit., 1987, pp. 399 y ss. 
patio, como sucedía en otros palacios castellanos, ya que las fuentes mencionan los escalones que había que subir ${ }^{23}$. En el centro del patio existía una fuente, de la que se conservaron restos hasta las últimas restauraciones y que aparece recurrentemente mencionada en las fuentes escritas ${ }^{24}$.

El patio tenía una doble galería de arcos, a la que posteriormente se añadió un tercer cuerpo en el ala norte ${ }^{25}$. La planta alta era la planta noble, a la que se accedía por una escalera principal, auténtica escalera de honor, cubierta con techumbre de madera y con decoración en sus muros, parcialmente conservada hasta el XIX:

"La espaciosa escalera conserva su artesonado con bien sentidas molduras y los elevados muros ostentan a su mayor altura hornacinas con bustos de personajes indumentados a la heroica" ${ }^{26}$.

Esta escalera, reproducida parcialmente en un plano realizado en $1860^{27}$, estaría situada en la esquina noroeste del patio. La escalera que se conserva actualmente, así como el espacio en el que se inscribe, es obra de Lampérez, restaurador de la Casa a comienzos del siglo XX. Es posible que la escalera original fuera semejante en disposición y proporciones a las escaleras de los palacios de Fuensalida, Ocaña, Torrijos o Cogolludo.

Desde esta escalera principal se accedía directamente a la galería oeste que quedaba así configurada como el núcleo principal de comunicaciones. Es en lo alto de la galería, junto a la escalera, donde Isabel la Católica esperó a su futura nuera, tal como describe Molinet

et trouvérent illecq environ neuf heures du soir, la royne de Castille et monseigneur le prince son fils, qui la receurent à l'entrée d'une galerie, où le bienveignant fut bien accepté et fort conjoy ${ }^{28}$.

23 En 1570, con motivo de la recepción de la reina Ana de Austria en Burgos se especifica: "La reyna nuestra señora, siendo apeada al subir de la escalera para el patio, vio su Magestad una grande figura de altura de una torre". Publicado por M.J. SANZ LUCAS, "Festivas demostraciones de Nimega y Burgos en honor de la Reina doña Ana de Austria”, Boletín del Seminario de Arte y Arqueología, 49 (1983), pp. 375-396. Vid. el anexo documental, pp. 391-395, especialmente p. 394.

${ }^{24}$ Así en la narración anónima de 1501: "au millieu de la place y auoit une fontaine fort belle, et y auoit fait ung tabernacle de bois pour y mettre dix torsses que faisoit beau voir", CHMEL, J. op. cit., 1841, p. 619 ; y nuevamente recepción de la reina Ana se menciona: "Delante de Neptuno estava una requíssima fuente con muchos caños de agua, toda de mil suertes de yervas mas altas de un estado que cierto era cosa de admiración", M.J. SANZ LUCAS, op. cit., 1983, p. 394. Además habría otras fuentes y pozos en el jardín en los que no podemos detenernos aquí.

25 A.C. IBÁÑEZ PÉREZ, op. cit., 19987, pp. 118-133 lo data a principios del siglo XVI. De la misma opinión es B. ALONSO RUIZ, La arquitectura tardogótica en Castilla: los Rasines. Santander, 2003, p. 80.

26 L. CANTÓN SALAZAR, Monografía histórico-arqueológica del Palacio de los Condestables en Castilla más comúnmente conocido por casa del Cordón, Burgos, 1884, p. 16; sigue esta descripción R. AMADOR DE LOS RÍOS, op. cit., 1888, pp. 702-708.

27 Publicado por A. IBÁÑEZ PÉREZ, op. cit., 1984, p. 141, il. 44

28 J. MOLINET, op. cit., 1828 , p. 68 
Sabemos que en este frente oeste existía otra escalera secundaria, una puerta hacia la calle que daba acceso al área de servicios y otra que comunicaba con el núcleo principal ${ }^{29}$. En el siglo XIX se reformó completamente este frente, creando una nueva escalera de honor y subdiviendo la galería en pequeñas habitaciones y a principios del XX se derribó toda esta fachada y se volvió a construir rentranqueada, dentro de un plan para ensanchar la calle. Por tanto su reconstrucción resulta hoy imposible.

Las habitaciones principales se encontraban en el ala sur, es decir, sobre la fachada y no al fondo del patio como era habitual en otros palacios castellanos contemporáneos $^{30}$. El desplazamiento de las habitaciones principales hacia la fachada ha sido generalmente estudiado en el caso del palacio de Cogolludo ${ }^{31}$ y analizado como una novedad italianizante que no fue aceptada con rapidez en la arquitectura civil castellana. Sin embargo, no se suele mencionar el precedente de la Casa del Cordón en esta aparición de los aposentos principales hacia la fachada. Esta solución se desarrolló en el palacio burgalés posiblemente por su función como palacio real: la sala y los aposentos principales debían estar sobre la fachada porque desde allí los reyes (y sus acompañantes) se podían asomar a la plaza para ver los espectáculos diversos que se organizaban en su honor ${ }^{32}$.

En el tiempo de las fiestas del casamiento del Príncipe, año de 1497, corríanse unos toros muy bravos en Burgos, mirándolos desde las casas del Condestable D. Bernardino de Velasco, el Rey, la Reina, el Príncipe e la Princesa Margarita, e las Infantas, las damas e muchos señores [...] y llegando debajo de una ventana baja de un entresuelo donde estaba mirando una dama muy principal[...]"33

29 E. GARCÍA DE QUEVEDO Y CONCELLÓN, "Libros burgaleses de memorias y noticias (14): Cosas memorables de Burgos por Arriada: continuación", Boletín De La Comisión Provincial De Monumentos Históricos y Artísticos De Burgos, 18 (1927), pp. 117-129. Sabemos que Carlos II utilizó esta puerta para entrar discretamente al palacio y evitar a la multitud que se agolpaba en la plaza frente a la fachada principal. A.C IBÁÑEZ PÉREZ, op. cit., 1984, p. 98-99.

30 Como es el caso de los palacios de Fuensalida, Torrijos, Ocaña o el Infantado por mencionar sólo los más próximos cronológicamente.

31 D. BAYON, L'architecture en Castille au XVIè siècle, Paris, 1967, pp. 73-76; F. MARÍAS, op. cit., 1994, pp. 170-172; J.L. PÉREZ ARRIBAS y J. PÉREZ FERNÁNDEZ, El palacio de los duques de Medinaceli en Cogolludo, Guadalajara, 2000, pp. 48-49

32 Una imagen contemporánea del palacio con sus habitantes asomándose por las ventanas nos la proporciona el cuadro de J. van Laethem en el castillo de la Follie, aunque en este caso se trate de la representación del cortejo fúnebre de Felipe el Hermoso y no de un acontecimiento festivo. Publicada por A.C. IBÁÑEZ PÉREZ, op. cit., p. 53, como de un anónimo flamenco. Sobre su atribución a Laethem vid. M.A. ZALAMA y R. DOMÍNGUEZ CASAS, "Jacob van Laethem, pintor de Felipe "el Hermoso" y Carlos V: precisiones sobre su obra”, Boletín del Seminario de Estudios Arte y Arqueología, 61 (1995), pp. 347-358.

33 G. FERNÁNDEZ OVIEDO, Batallas y quinquagenas, Madrid, 2000, t. II p. 156. El primero en publicar esta noticia fue el DUQUE DE MAURA, El príncipe que murió de amor. Don Juan, primogénito de los Reyes Católicos, Madrid, 2000 (1944), p. 180. 
La configuración de estos aposentos principales puede intuirse a partir de las fuentes escritas ${ }^{34} \mathrm{y}$ de varios planos del palacio que se dibujaron en el siglo XVIII con motivo de las obras proyectadas para transformarlo en capitanía general ${ }^{35}$.

La sala principal de aparato ocupaba la mayor parte del ala sur y sus dimensiones pueden verse en el plano del XIX, que indica con claridad los muros maestros que marcaban las divisiones principales del palacio medieval. Esta sala aparece descrita en la crónica de 1501 como:

"una bella sala grande muy bien cubierta [de tapices] a los dos lados y por arriba, tan bien que parecía un cielo. [...]Y era la tapicería de verdura que era hermoso de ver, y fueron los sarracenos los que la habían entoldado tan bien. Hacen maravilla al colgar tapicerías y al trabajar las casas de mortero y de yeso, [...] que cuando se mira parece piedra blanca tallada, tan bien está hecho [...]. Y en la dicha sala había un lugar en lo alto como una galería donde había órganos que tocaban cuando monseigneur entró en la sala para ir a su habitación" ${ }^{36}$.

Por tanto, tenía una galería en lo alto para colocar a los músicos ${ }^{37}$. En otro punto del texto se menciona que en un lateral había un estrado sobre cuatro escalones, todo cubierto de alfombras, y un gran dosel ${ }^{38}$. Además sabemos que contaba con una

34 J. MOLINET, Chroniques, J.A. BUCHON (ed.), Paris, 1828, p.68 y 74, en relación con las bodas del príncipe Juan y Margarita y p. 182, con motivo del viaje de Juana y Felipe el Hermoso; L. PADILLA, Crónica de Felipe I llamado el Hermoso, M. SALVÁ y P. SAINZ DE BARANDA, Colección de documentos inéditos para la Historia de España, vol. VIII, Madrid, 1846, pp. 43-45 y 84-85; A. LALAING, "Voyage de Philippe le Beau en Espagne, en 1501", M. GACHARD, Voyages des Souverains des Pays-Bas, Bruxelles, 1874, pp. 164-165. Con una mayor profusión de detalles relata este viaje la crónica anónima J. CHMEL, op. cit., 1841, pp. 607-620. Algo más tardíos pero enormemente interesantes son los textos escritos con motivo de la recepción de doña Ana de Austria (M.J. SANZ LUCAS, op. cit., 1983) y de la visita del cabildo a Felipe III (A. BLANCO DÍEZ, "Proyección de recuerdos de la primera mitad del siglo XVII. Continuación", Boletín de la Comisión Provincial De Monumentos y de la Institución Fernán González De La Ciudad De Burgos, 106 (1949), pp. 33-44, esp. 34-35). En A. ZALAMA y P. ANDRÉS, La colección artística de los Condestables de Castilla en su palacio burgalés de la Casa del Cordón, Burgos, 2002, obra fundamental para el estudio de este edificio y de sus obras artísticas, se hace una reconstrucción de las estancias partiendo de este último texto de la que diferimos en algunos puntos, puesto que no creemos que la capilla estuviese situada en el torreón oriental.

35 A. IBÁÑEZ PÉREZ, op. cit., 1987, pp. 99 y 141.

36 La traducción es mía. El original, en francés, J. CHMEL, op. cit., 1841, pp. 609 y ss. Sobre el uso del término entoldar, vid. la contribución de O. PÉREZ MONZÓN en este mismo volumen.

37 Sabemos que el Condestable tenía sus propios ministriles que, en ocasiones, rendían servicio a otros nobles. Así en julio de 1485 consta en las cuentas del camarero del duque de Medinaceli: “Que distes por my mandado a çinco menestriles altos del condestable de Castilla dosientos e sesenta e çinco marauedis a cada vno de merçed que yo les hize, que son todos mill e tresientos e veynte e çinco marauedis" Archivo Ducal de Medinaceli, Medinaceli, leg. 68. Agradezco la noticia a Francisco de Paula Cañas Gálvez.

38 «en ladite sale y auoit fait ung tresbeau merchepied et y falloit monter a quatre degrez, et dessus le dit marchepied y auoit deux chayeres counertes de drap dor et chacun ung coussin de mesme et le beau dosseret aussi a tout belles fringes, et estoit le ciel du dosseret aussi long que le marchepied, et estoit tout le marchepiedt et les degrez tenduz et couners de beauz tapis, tellement que cestoit riche chose a veoir». CHMEL, op. cit., 1841, pp. 609. 
chimenea, que apareció tapiada durante las reformas del siglo XIX, y un rodapié de azulejos que Bosarte alcanzó a ver ${ }^{39}$.

Esta sala se comunicaba con los aposentos reales, como parece desprenderse de la cita anterior que continua:

“[...] monseigneur entró en la sala para ir a su habitación. Y cuando monseigneur fue a su habitación y se hubo cambiado de vestiduras y cuando estuvo preparado pasó a una habitación detrás de la suya donde estaban los caballeros de España que conversaban".

El que se accediera a las habitaciones privadas de Felipe el Hermoso a través de la gran sala de banquetes no era inhabitual, ya que Lalaing testimonia la misma distribución en Toledo:

"El jueves siete de julio dio el archiduque de comer en forma de banquete al rey y a la reina y a la princesa, en una sala adornada con su buena tapicería, unida a la cámara del rey donde, sentados como en otros banquetes, fueron muy bien servidos a la moda de nuestro país" $" 40$

En el caso burgalés, tras la habitación de Felipe había todavía otra que cumplía la función de espacio semiprivado, donde el príncipe podía reunirse con los caballeros para hablar o, como sucedió varias noches, compartir vino y dulces ${ }^{41}$. Esta estancia correspondería con la sala cuadrada de la torre este, que se cubría con una techumbre ochavada de madera ${ }^{42}$ indicando la importancia principal de este espacio. Ya no es la gran sala de recepciones, como en Medina de Pomar, puesto que esta función la desempeña la gran sala rectangular. Es una sala intermedia de recepciones semipúblicas, comunicada con el dormitorio del archiduque, espacio más privado, y con la galería este que daba al jardín por donde entrarían los invitados.

Esta disposición de las habitaciones encajaba con las necesidades tanto de los reyes castellanos como del duque borgoñón que en su etiqueta de 1496 dictaba:

"Item, voulons que ordre soit tenu ès entrées de nos chambres, tant des pensionnaires, chambellans, maîtres d'hôtel et gentilshommes, à savoir: qu'il y aura une chambre

39 I. BOSARTE, Viaje artístico a varios pueblos de España, Madrid, Turner, 1978 [1 ed. 1804], pp. 254255. En 1884 este rodapié había desaparecido y la estancia estaba completamente deteriorada: L. CANTÓN SALAZAR, op. cit.,1884, p. 16.

40 Cit. J. GARCÍA MERCADAL, Viajes de extranjeros por España y Portugal: Desde los tiempos más remotos hasta fines del siglo XVI, Madrid, 1952, t. I, p. 437.

41 J. CHMEL, op. cit., 1841, vol 2, p. 612 y 614-615. Era tradición que el anfitrión obsequiase a sus huéspedes con lo que las fuentes denominan confitures o épices: mermeladas, frutas confitadas y preparaciones líquidas con especias. Una escena muy similar se desarrolló en este mismo viaje en Blois, pero en este caso los platos fueron llevados a las habitaciones privadas. Vid. M. CHATENET et P.G. GIRAULT, Fastes de cour. Les enjeux d'un voyage princier à Blois en 1501, Rennes, 2010, pp. 47-48.

42 " [...] un pedazo de texao arrimado al artesonado de la media naranja que se halla en los quartos principales que miran al mercao, que dicho texao tiene veinte pies en quadro, que es preciso reedificar", Condiciones para hacer una obra en la casa del Cordón en 1744, publicado por A. IBÁÑEZ PÉREZ, op. cit., 1987, pp. 343. 
devant celle où nous coucherons, en laquelle chambre seront les huissiers qui garderont la porte, et y entreront tous pensionnaires, chambellans, maîtres d'hôtel et gentilshommes, et si au lieu où nous serons y ait deux chambres devant la notre où nous coucherons $[\ldots]^{\prime \prime} 43$.

Etiqueta muy similar a la que varios años antes los reyes habían establecido para la corte del príncipe Juan ${ }^{44}$.

Además de esta serie de cuartos principales sobre la fachada, tenemos noticia de la existencia de una capilla, en la que Mencía de Mendoza pide en su testamento "encomienden mi cuerpo y pásenme a la capilla que tengo en mi casa" ${ }^{45}$ y que aparece descrita en la crónica de 1501 de forma bastante genérica:

"muy bella y rica con pintura de oro y parece un pequeño paraíso de lo bello que es, y estaba todo cubierto de bellas tapicerías que pertenecían al Condestable" ${ }^{46}$.

Sobre su situación exacta solo se pueden realizar hipótesis. Sabemos que estaba en la planta alta y que tenía una pared de cantería que miraba hacia el exterior, donde se documenta la apertura de dos ventanas en $1601^{47}$. Muy probablemente se situaría en el ángulo noreste ${ }^{48}$, mirando hacia el jardín que, no podemos olvidar, originalmente estaba concebido como un sacromonte ${ }^{49}$.

En definitiva, la Casa del Cordón era un palacio ya completamente especializado, complejo, con espacios diferenciados: la parte noble, con las unidades de cámara, sala, y antecámara, una capilla y una zona de servicios con las cocinas, letrinas, etc. Además, como en otros palacios contemporáneos, habría dos zonas diferenciadas para los aposentos masculinos y femeninos, algo que parece desprenderse de las fuentes pero que nunca llega a indicarse de forma explícita. Y además habría que

43 Cit. K. DE JONGE, "Espacio ceremonial. Intercambios en la arquitectura palaciega entre los Países Bajos borgoñones y España en la Alta Edad Moderna (1520-1620)", K. DE JONGE, B. GARCÍA GARCÍA y A. ESTEBAN ESTRÍNAGA, el legado de Borgoña. Fiesta y ceremonia cortesana en la Europa de los Austrias (1454-1658), Madrid, 2010, nota 9, pp. 82-83.

44 Conocida gracias al informe de Gonzalo Fernández de Oviedo para Carlos V. Vid. G. FERNÁNDEZ DE OVIEDO, Libro de la cámara real del Príncipe Don Juan, oficios de su casa y servicio ordinario, S. FABREGAT BARRIOS (ed.), Valencia, 2006, esp. pp. 93 y ss.

45 F. PEREDA, "Mencía de Mendoza (+1500), mujer del I Condestable de Castilla", F. PEREDA, B. ALONSO y M.C. DE CARLOS, Patronos y coleccionistas. Los Condestables de Castilla y el arte (siglos $X V$-XVII), Valladolid, 2005, pp. 11-119. Vid nota 127, pp. 54 y ss. donde se transcribe el testamento íntegro.

46 J. CHMEL, op.cit., 1841 , p. 614.

47 La situación en la planta alta puede ser deducida del texto de la visita del cabildo a Felipe III (A. BLANCO DÍEZ, op. cit., 1949), como ya analizaron M.A. ZALAMA y P. ANDRÉS, op. cit., 2002, p. 35 y ss. El documento de concierto para hacer obras en la Casa del Cordón ha sido transcrito y publicado por A. IBÁÑEZ PÉREZ, op. cit., 1987, pp. 338-340.

48 A. Ibáñez la sitúa en la crujía norte, interpretando la documentación anterior. M.A. Zalama y P. Andrés la sitúan en la torre este que, a nuestro entender, parece haber sido una sala de aparato. Si de hecho estaba en crujía norte, cosa que parece probable (puesto que la sur estaba ocupada con las salas principales y la este con la galería hacia el jardín) y daba hacia el exterior, el ángulo noreste, con vistas hacia el jardín y no hacia el patio de servicio parece el lugar más probable para situarla.

49 Además se ordena abrir otra ventana en la pared de ladrillo, posiblemente el tabique de división interno, que miraría hacia las galerías del patio. Vid. A. IBÁÑEZ PÉREZ, op. cit., 1987, pp. 338-334. 
destacar por su novedad el hecho de que las habitaciones principales se sitúen sobre la fachada y la apertura de una galería lateral hacia un jardín.

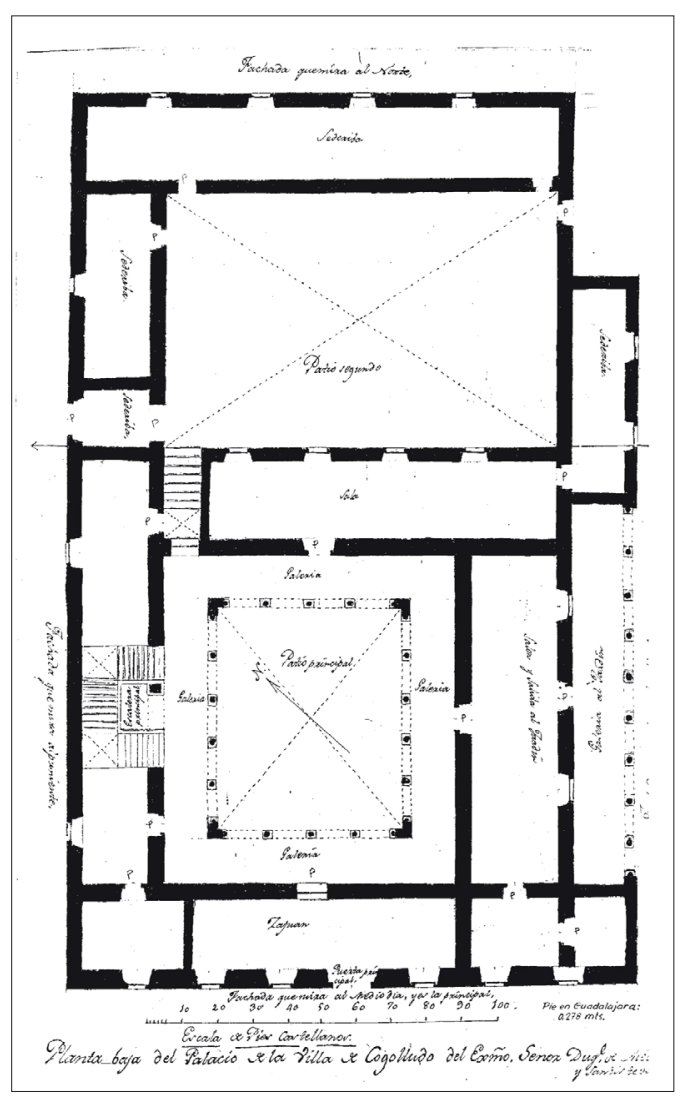

Fig. 6. Planta de Cogolludo. S. XVIII Archivo Ducal de Medinaceli. Sección Cogolludo, Legajo 2, n 54 (J.L PÉREZ ARRIBAS y J. PÉREZ FERNÁNDEZ. El palacio de los duques de Medinaceli en Cogolludo, 2000, p. 124).

Frente a Medina de Pomar, con salas mucho más plurifuncionales y menor división entre espacios públicos y privados, la Casa del Cordón plantea un modelo codificado de palacio nobiliario especializado. Este palacio incluye todos los espacios que se necesitan cotidianamente, pero también los que deben ser utilizados en ocasiones especiales en las que se requiere seguir un protocolo específico, especialmente cuando se convierte en residencia real. Por supuesto, la casa estaría sometida a continuas reformas añadiendo tabiques y tapices, dividiendo o unificando espacios en función de las necesidades inmediatas ${ }^{50}$, pero los espacios principales y su organización funcional estaban ya establecidos.

50 Vid. R. DOMÍNGUEZ CASAS, op. cit., 1994, pp. 302-307. 
Este modelo de palacio aparece también en Cogolludo, construido en fechas cercanas $^{51}$ y cuya planta es conocida gracias a un dibujo del siglo XVIII ${ }^{52}$ (fig.6), recientemente confirmado por excavaciones arqueológicas. En él vemos una disposición muy similar a la de la Casa del Cordón, con las habitaciones principales sobre la fachada, ordenadas en torno a un patio central al que se accede mediante un zaguán con puerta desenfilada respecto al eje central. También posee una galería abierta hacia un jardín, una capilla situada en la planta noble y un segundo patio trasero organizando la zona de servicios, así como un núcleo de comunicaciones principal organizado por la gran escalera de honor.

Evidentemente, el vocabulario arquitectónico no es el mismo, como no es la misma la concepción del jardín, pero la especialización y organización de los espacios convergen hacia soluciones comunes que no se pueden atribuir únicamente a la llegada de artistas y modelos italianos y en las que hay que valorar también la propia evolución arquitectónica hispánica. Los dos palacios de los Velasco son dos ejemplos punteros de palacio nobiliario de su momento; incorporaron novedades y contribuyeron a la formación de modelos que se posteriormente desarrollaron en otros edificios de la nobleza castellana ${ }^{53}$.

51 Las fechas tradicionalmente propuestas por Gómez Moreno (1479-1492) se corresponden con las fechas (c. 1494) que parecen deducirse de la documentación conservada de las murallas publicada por T. LAGUNA PAÚL y A.J LÓPEZ GUTIÉRREZ, "Los recintos amurallados y el urbanismo en Cogolludo de 1176 a 1505", Laboratorio de Arte: Revista del Departamento de Historia del Arte, 1 (1988), pp. $29-52$.

52 Archivo Ducal de Medinaceli. Sección Cogolludo, Legajo 2, $\mathrm{n}^{\circ}$ 54. Publicado por A. TRALLERO SANZ, "La importancia de una planta del siglo XVIII en el conocimiento del palacio de los duques de Medinaceli en Cogolludo", Actas del V Congreso de la Asociación de Profesores de Expresión Gráfica Aplicada a la Edificación, Burgos, 1999, pp. 347-366 y por J.L PÉREZ ARRIBAS y J. PÉREZ FERNÁNDEZ. op.cit., 2000, p. 124.

53 P. DE LA RIESTRA, El Claustro de Comendadoras de Santiago en Valladolid y el patio Welser de Nuremberg, Valladolid, 1994 propone que el patio de la Casa del Cordón se convierte en modelo de prestigio, utilizado en otras construcciones nobiliarias y monásticas posteriores. Quizá merezca la pena profundizar en el papel de la planta del palacio burgalés dentro de la evolución de los palacios hispanos. 